\title{
Correspondence
}

\section{Asthma-contrasts in care}

Sir,-I congratulate you on the new appearance and new plans for Thorax. I look forward both to signed leaders and to signed correspondence.

I have one criticism to make of the otherwise admirable and important leader that you wrote on "Asthma-contrasts in care" (February 1978). You refer to "epidemiologists, who have successfully publicised the dubious toxicity of our most useful remedies without pointing out the therapeutic alternatives." This is a serious accusation to make of professional colleagues and you should be more explicit, with a reference to the "publicising" of which you consider them guilty, and with your reasons for asking epidemiologists to make therapeutic recommendations.

I presume that you must be referring to the account given by Speizer and Doll of the epidemic of asthma deaths in the $1960 \mathrm{~s}$, which were attributed to the overuse of strong isoprenaline aerosols. They carried out no publicity but only described their findings and suggested a possible cause. The Department of Health subsequently sent out the warning note to doctors that was followed by an immediate drop in asthma deaths. Has any clinician saved as many lives of asthmatics in his whole career as were saved by this simple public health measure? Have you any other explanation of the rise and fall of asthmatic deaths in the 1960s? If not, I consider it most improper to attribute doctors' resistance to prescribing newer, safer aerosols to a factual account of an epidemic and an explanation that seems to have been correct.

What we now need to consider is how to educate over-conservative and ignorant doctors to use safe modern methods of asthma control. You draw an apt parallel with diabetics who can monitor their own treatment as asthmatics can now do with a much cheaper Wright mini peak-flow meter. Diabetics have a patients' association that helps them with their problems. At present, asthmatics have no national association. I and others interested in this question are trying to form one. If any readers of Thorax would like to join in and help I should be glad to hear from them.

CHARLES FLETCHER London SW10 9SA.

REPLY - My intention in referring to hospital physicians and epidemiologists in the article was to suggest that they were, at least in part, responsible for a failure in communication within the profession. The epidemiologists whom I had particularly in mind were those who still persist in teaching medical students that pressurised aerosol bronchodilators (unspecified) were the cause of the epidemic of deaths and therefore by implication are still harmful. This message in my experience has been made sufficiently open to public knowledge (or publicised) within the profession that very many doctors still will not use the newer and more selective drugs. I did not refer to the work of Speizer and Doll, which drew attention to the epidemic of deaths and suggested the possibility of an association with isoprenaline inhalers.

Whether the inhalers were the cause of the excess of deaths is not definitely established, although there certainly has been a fall in the number of deaths from asthma in Britain. Other possible explanations could be changes in the readiness of physicians to prescribe adequate doses of corticosteroids or an increased awareness by hospital physicians to take severe asthma seriously. We do not know the explanation but we do know how to treat asthma. I hope my article drew attention to some areas where we could do better. One such area is the formation of a patients' association, and I hope our readers will support Professor Fletcher in this. 